\title{
SALIVARY CARBONIC ANHYDRASE VI, ZINC SULFATE TASTE ACUITY AND FREQUENCY OF ILLNESS: A PILOT STUDY
}

\author{
${ }^{1}$ Matthew J. Zdilla and ${ }^{2}$ Leah D. Starkey \\ ${ }^{1}$ Department of Natural Sciences and Mathematics, \\ West Liberty University, West Liberty, West Virginia, 26074, USA \\ ${ }^{2}$ West Virginia University School of Medicine, Morgantown, West Virginia, 26506, USA
}

Received 2014-06-28; Revised 2014-07-04; Accepted 2014-07-08

\begin{abstract}
Salivary Carbonic Anhydrase VI (CA6) is a zinc-dependent metalloenzyme which may be important for normal taste function. Though many taste assessment methods exist, the assessment of zinc sulfate taste acuity is a method that has been suggested to have diverse relationships to human health. A double-blinded pilot study was conducted among 21 individuals to analyze the relationships between salivary CA6 concentrations, zinc sulfate taste acuity and self-reported frequency of illness. ELISA was performed to quantify CA6 concentrations, the Bryce-Smith and Simpson "Zinc Taste Test" (BS-ZTT) protocol and a Taste Intensity Visual Analog Scale (TI-VAS) were utilized to assess zinc sulfate taste acuity and a health history questionnaire was used to determine the frequency of illness. A statistically significant correlation existed between CA6 concentration and zinc sulfate taste acuity determined via the BS-ZTT $\left(r_{s}=0.62 ; p=\right.$ 0.03). A moderate statistically significant negative correlation was found between self-reported frequency of illness and BS-ZTT scores $\left(r_{s}=-0.64, p=0.034\right)$. Likewise, a strong statistically significant negative correlation was found between self-reported frequency of illness and TI-VAS scores $\left(r_{s}=-0.81, p=0.003\right)$. The results of this pilot study suggest that zinc sulfate taste acuity may be reflective of salivary CA6 concentration in addition to being a retrospective indicator of illness frequency.
\end{abstract}

Keywords: Zinc Taste Test, Gustin, Ageusia, Hypogeusia, Dysgeusia, Immunity

\section{INTRODUCTION}

\subsection{Carbonic Anhydrase VI}

Salivary Carbonic Anhydrase VI (CA6) is a zincdependent metalloenzyme first purified from human saliva in 1987 (Murakami and Sly, 1987). However, it was determined that CA6 was identical to gustin, a previously identified salivary protein (Thatcher et al., 1998). CA6 is released from acinar cells of the parotid, submandibular and von Ebner's glands (Kivelä et al., 1999). Carbonic anhydrase enzymes, in general, function in the reversible reaction $\mathrm{H}^{+}+\mathrm{HCO}_{3}{ }^{-} \leftrightarrow \mathrm{H}_{2} \mathrm{O}+\mathrm{CO}_{2}$ and are involved in a number of physiological mechanisms including $\mathrm{pH}$ balance (Sly and $\mathrm{Hu}, 1995)$. Salivary CA6 has been documented as an important factor in oral $\mathrm{pH}$ balance, normal taste bud development and taste acuity (Kivelä et al., 1999; Leinonen et al., 1999; Henkin et al., 1999a; 1999b). Research performed among individuals with low CA6 levels, aberrant taste bud morphology and impaired taste function has demonstrated that, upon zinc supplementation, CA6 levels increase and, later, taste bud morphology normalizes and taste function improves (Henkin et al., 1999a).

\subsection{Zinc Sulfate Taste Acuity Assessment}

While many methods of taste assessment exist, one method, the "Zinc Taste Test" (ZTT), has been hypothesized to be reflective of bioavailable zinc levels. A ZTT employs a solution of zinc sulfate in distilled Sciences and Mathematics, West Liberty University, West Liberty, West Virginia, 26074, USA 
water. Taste acuity, as measured by ZTTs, has been correlated with serum zinc levels throughout pregnancy (Garg et al., 1993), as well as zinc levels in sweat (Eaton et al., 2004). The first reported use of a ZTT was a case study documenting correlations between taste acuity and the weight and demeanor of a female with anorexia (Bryce-Smith and Simpson, 1984a; 1984b). Later, a 1993 article reported a significant difference between pregnant "non-tasters" and "tasters" with regard to incidence of having previously given birth to a growth retarded infant (Mahomed et al., 1993). The authors of the 1993 study also reported taste acuity of the zinc sulfate solution to be predictive of the development of diastolic hypertension during pregnancy (Mahomed et al., 1993). Therefore, zinc sulfate taste acuity may have relationships with diverse aspects of health. Many ZTT protocols have been reported; however, no consistent protocol has been adopted among studies (Gruner and Arthur, 2012).

\subsection{Purpose of the Study}

Because salivary CA6 is structurally dependent upon zinc and both CA6 levels and zinc have been tied to taste function, the study was designed to explore relationships between salivary CA6 concentration and zinc sulfate taste acuity. A $0.1 \%$ zinc sulfate solution was used in conjunction with a Taste Intensity Visual Analog Scale (TI-VAS) to assess taste acuity due to the aforementioned reports linking the zinc sulfate taste acuity to plasma and sweat zinc levels. Because previous studies noted findings not exclusive to taste acuity, the study was also designed to examine general immune function, a capacity dependent upon adequate zinc levels (Knoell and Liu, 2010; Prasad, 2008, 2009), by retrospectively measuring frequency of illness.

\section{MATERIALS AND METHODS}

\subsection{Sampling}

The experimental protocol was approved by the West Liberty University Human Subjects Committee. Student volunteers $(n=21)$ were briefed on their role in the study. Informed consent was obtained from each individual prior to experimentation. A total of 21 individuals (10 females and 11 males) aged 18-29 years old (18-29 female age range; $20.9 \pm 3.1$ mean \pm SD; $18-27$ male age range; $20.8 \pm 2.4$ mean \pm SD) participated in the study. The control group consisted of five males and five females and the experimental group consisted of six males and five females, respectively.

\subsection{Saliva Collection}

As per the original Bryce-Smith and Simpson (1984b), volunteers were instructed not to eat, drink, use tobacco products, or brush their teeth within $2 \mathrm{~h}$ of participation. Because CA6 secretion has been demonstrated to follow a circadian rhythm (Parkkila et al., 1995), all samples were collected from participants simultaneously. Each volunteer was directed to donate $10 \mathrm{~mL}$ of whole saliva (unstimulated) into a sterile 15 $\mathrm{mL}$ conical tube for analysis.

\subsection{Carbonic Anhydrase VI Quantification}

Salivary samples were assayed for CA6 concentrations. Concentrations of CA6 in each salivary sample were quantified in duplicate via sandwiched ELISA. Collection protocol and assay were followed according to the protocol outlined from an ELISA kit (USCN Life Science Inc. ELISA kit). Microtiter plates coated with monoclonal antibodies specific to human CA6 were stored at $-20^{\circ} \mathrm{C}$. Salivary samples were centrifuged at $1000 \times \mathrm{g}$ for $20 \mathrm{~min}$. Supernatant fluid was removed and stored at $-80^{\circ} \mathrm{C}$. Freeze/thaw cycles were avoided. Prior to testing, samples were brought to room temperature in an ice bath.

\subsection{Health History Questionnaire}

Each participant filled out a Health History Questionnaire (HHQ). Frequency of illness data was gathered from each participant's self-reported response to a question asking, over the past three years, about how often, per year, the participant was sick.

\subsection{Bryce-Smith and Simpson Zinc Taste Test}

The study was conducted in a double-blind fashion. The taste perception of the control group $(n=10)$ was tested with $10 \mathrm{~mL}$ of distilled water rather than $10 \mathrm{~mL}$ of $0.1 \%$ zinc sulfate solution administered to the experimental group $(n=11)$. Each subject was instructed to drink, but not swallow, the $10 \mathrm{~mL}$ of test solution. The subject's reaction to the solution was ranked by the researcher according to the BS-ZTT protocol. The subject was scored on a scale ranging from 1 to 4 . A score of " 1 " was given to individuals in which "no specific taste or other sensation [was] noticed, even after the solution has been kept in the mouth for about 10 sec;" "2" when "no immediate taste [was] noted, but after a few seconds a slight taste variously described as 'dry,' 'mineral,' 'furry,' or (more rarely) 'sweet' [developed];" "3" when "a definite though not strongly unpleasant taste [was] noted almost immediately and 
[tended] to intensify with time;" and " 4 " when "a strong and unpleasant taste [was] noted immediately." All individuals were graded by the same researcher.

\subsection{Taste Intensity Visual Analog Scale}

After the subject was ranked according to the BS-ZTT, the individual was asked to complete a Taste Intensity Visual Analog Scale (TI-VAS). Each subject was instructed to mark a perpendicular line through a continuous line measuring $100 \mathrm{~mm}$ to rate the intensity at which they perceived the test substance. At the left side of scale "No taste" was written and on the right, "Extremely intense taste." The intensity was later measured from the left anchor bar to the nearest whole millimeter. The measurement was recorded as the TI-VAS score.

\subsection{Statistical Analysis}

The statistical software, Statistical Package for the Social Sciences (IBM SSPS Statistics 20) was used for statistical analysis and graphical representations depicted herein.

\section{RESULTS}

\subsection{Zinc Sulfate Taste Acuity}

Taste acuity data from the control group $(n=10)$ averaged $1.4 \pm 0.5$ (mean \pm SD) as gauged by the BS-ZTT and $7.3 \pm 6.4$ as gauged by the TI-VAS. Taste acuity from the experimental group $(\mathrm{n}=11)$ averaged $2.3 \pm 0.9$ as rated by the BS-ZTT and $29 \pm 29.4$ as gauged by the TIVAS (Table 1). Zinc sulfate taste acuity of the control

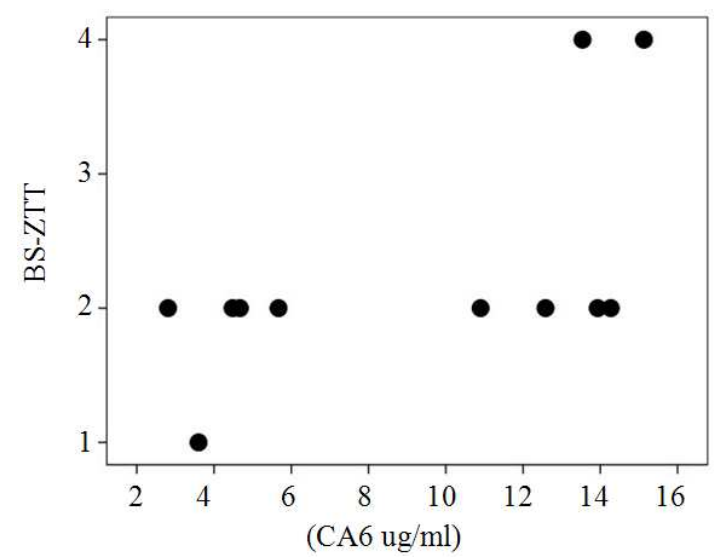

(a) and experimental groups were compared via a MannWhitney $U$ test which noted a significant difference between BS-ZTT scores $(U=23.0 ; Z=-2.55 ; p=0.011)$ between the two groups. Likewise, a significant difference was noted between groups with regard to taste acuity as measured by TI-VAS scores $(U=25.5 ; Z=$ $2.09 ; \mathrm{p}=0.037$ ) (Table 2). Subjective descriptions of the zinc sulfate solution are outlined in Table 3.

\subsection{Zinc Sulfate Taste Acuity and Carbonic Anhydrase VI}

Salivary CA6 concentrations ranged from 1.7-15.1 ug $\mathrm{mL}^{-1}\left(\mathrm{n}=21 ; 9.1 \pm 4.9 \mathrm{ug} \mathrm{mL}{ }^{-1}\right.$, mean $\left.\pm \mathrm{SD}\right)$ among the total population. Concentrations of $\mathrm{CA} 6$ in the experimental group averaged $9.2 \pm 4.9 \mathrm{ug} \mathrm{mL}^{-1}$ with a range of 2.8-15.1 ug $\mathrm{mL}^{-1}$ (Table 1). Among those individuals who were tested with distilled water, a Spearman's rank-order correlation test noted no significant correlation between CA6 concentration and BS-ZTT scores $\left(r_{s}=-0.21 ; \mathrm{p}=0.55, \mathrm{n}=10\right)$ nor was there a significant correlation between CA6 concentrations and TI-VAS scores $\left(r_{s}=0.12 ; \mathrm{p}=0.74, \mathrm{n}\right.$ $=10$ ). However, among those individuals tested with the $0.1 \%$ zinc sulfate solution, a statistically significant positive correlation $\left(r_{s}=0.62 ; p=0.03, \mathrm{n}=11\right)$ was found between CA6 concentrations and BS-ZTT scores (Fig. 1A). Among those individuals administered the $0.1 \%$ zinc sulfate solution, a positive correlation, however not statistically significant, was calculated between the average CA6 concentrations and TI-VAS scores $\left(r_{s}=0.56, p=0.07, \mathrm{n}=11\right)$ (Fig. 1B).

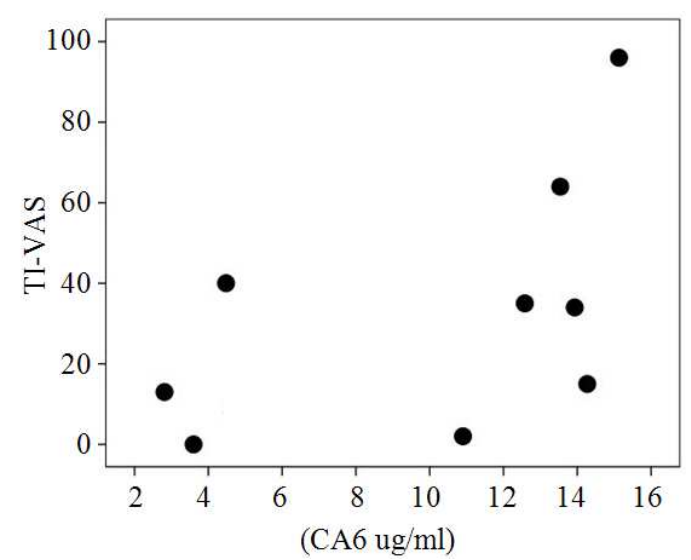

(b)

Fig. 1. Among 11 individuals tested with a $0.1 \%$ zinc sulfate solution, (A) salivary carbonic anhydrase VI (CA6) concentration significantly correlated with zinc sulfate taste acuity as measured by the BS-ZTT ( $r s=0.62 ; p=0.03)$ and, likewise, (B) zinc sulfate taste acuity measured by the TI-VAS was correlated to CA6 concentrations, however the correlation was not statistically significant $(r s=0.56, p=0.07)$ 
Matthew J. Zdilla and Leah D. Starkey / American Journal of Immunology 10 (2): 107-113, 2014

Table 1. Descriptive statistics of carbonic anhydrase VI concentrations, zinc taste test, taste intensity visual analog scale and frequency of illness data among the total population, control and experimental groups and among sexes.

\begin{tabular}{|c|c|c|c|c|c|}
\hline$\underline{\text { Parameter }}$ & Population & Min & Max & Mean & $\pm \mathrm{SD}$ \\
\hline \multicolumn{6}{|c|}{ Carbonic anhydrase VI concentration (ug/ml) } \\
\hline & Total population $(\mathrm{n}=21)$ & 1.0 & 10.0 & 2.5 & 2.0 \\
\hline & Females $(\mathrm{n}=10)$ & 2.8 & 14.7 & 10.0 & 4.6 \\
\hline & Males $(n=11)$ & 1.0 & 4.0 & 2.0 & 1.1 \\
\hline & Control Group $(\mathrm{n}=10)$ & 1.7 & 14.8 & 9.0 & 5.1 \\
\hline & Females $(n=5)$ & 3.4 & 14.7 & 10.9 & 4.3 \\
\hline & Males $(\mathrm{n}=5)$ & 1.7 & 14.8 & 7.2 & 5.5 \\
\hline & Experimental Group $(\mathrm{n}=11)$ & 2.8 & 15.1 & 9.2 & 4.9 \\
\hline & Females $(n=5)$ & 2.8 & 13.9 & 9.1 & 5.2 \\
\hline & Males $(n=6)$ & 3.6 & 15.1 & 9.3 & 5.2 \\
\hline \multicolumn{6}{|c|}{ Bryce Smith and Simpson zinc taste test* } \\
\hline & Total population $(\mathrm{n}=21)$ & 1.0 & 4.0 & 1.9 & 0.9 \\
\hline & Females $(n=10)$ & 1.0 & 4.0 & 1.9 & 0.9 \\
\hline & Males $(\mathrm{n}=11)$ & 1.0 & 4.0 & 1.8 & 0.9 \\
\hline & Control Group $(\mathrm{n}=10)$ & 1.0 & 2.0 & 1.4 & 0.5 \\
\hline & Females $(n=5)$ & 1.0 & 2.0 & 1.4 & 0.5 \\
\hline & Males $(\mathrm{n}=5)$ & 1.0 & 2.0 & 1.4 & 0.5 \\
\hline & Experimental group $(\mathrm{n}=11)$ & 1.0 & 4.0 & 1.3 & 0.9 \\
\hline & Females $(\mathrm{n}=5)$ & 2.0 & 4.0 & 2.4 & 0.9 \\
\hline & Males $(n=6)$ & 1.0 & 4.0 & 2.2 & 1.0 \\
\hline \multicolumn{6}{|c|}{ Taste intensity visual analog scale } \\
\hline & Total population $(\mathrm{n}=21)$ & 0.0 & 96.0 & 18.7 & 24.0 \\
\hline & Females $(n=10)$ & 0.0 & 64.0 & 20.2 & 20.0 \\
\hline & Males $(n=11)$ & 0.0 & 96.0 & 17.3 & 30.0 \\
\hline & Control Group $(\mathrm{n}=10)$ & 0.0 & 18.0 & 7.3 & 6.4 \\
\hline & Females $(n=5)$ & 0.0 & 18.0 & 9.8 & 6.6 \\
\hline & Males $(\mathrm{n}=5)$ & 0.0 & 14.0 & 4.8 & 5.7 \\
\hline & Experimental group $(\mathrm{n}=11)$ & 0.0 & 96.0 & 29.0 & 29.4 \\
\hline & Females $(n=5)$ & 2.0 & 64.0 & 30.6 & 24.2 \\
\hline & Males $(n=6)$ & 0.0 & 96.0 & 27.7 & 35.4 \\
\hline \multirow[t]{9}{*}{ Frequency of illness $\dagger$} & Total Population $(\mathrm{n}=21)$ & 1.0 & 10.0 & 2.5 & 2.0 \\
\hline & Females $(n=10)$ & 1.0 & 10.0 & 3.1 & 2.7 \\
\hline & Males $(n=11)$ & 1.0 & 4.0 & 2.0 & 1.1 \\
\hline & Control Group $(\mathrm{n}=10)$ & 1.0 & 10.0 & 3.1 & 2.7 \\
\hline & Females $(n=5)$ & 2.0 & 10.0 & 4.4 & 3.4 \\
\hline & Males $(n=5)$ & 1.0 & 3.0 & 1.8 & 0.8 \\
\hline & Experimental Group $(\mathrm{n}=11)$ & 1.0 & 4.0 & 1.9 & 1.1 \\
\hline & Females $(n=5)$ & 1.0 & 3.0 & 1.7 & 0.8 \\
\hline & Males $(n=6)$ & 1.0 & 4.0 & 2.1 & 1.3 \\
\hline
\end{tabular}

*interpreted via the Bryce-Smith and Simpson (1984b); †data represents the self-reported number of illnesses per year

Table 2. Differences in control and experimental groups with regard to carbonic anhydrase VI concentrations, zinc taste acuity and frequency of illness

\begin{tabular}{|c|c|c|c|c|c|c|}
\hline \multirow[b]{2}{*}{ Parameter } & \multicolumn{2}{|l|}{ Mean \pm SEM } & \multirow[b]{2}{*}{$\mathrm{U}$} & \multirow[b]{2}{*}{$\mathrm{W}$} & \multirow[b]{2}{*}{$\mathrm{Z}$} & \multirow[b]{2}{*}{$\mathrm{p}$} \\
\hline & Control $(n=10)$ & Experimental $(n=11)$ & & & & \\
\hline Carbonic anhydrase VI (ug/ml) & $9.04 \pm 1.60$ & $9.23 \pm 1.49$ & 49.0 & 104.0 & -.423 & 0.673 \\
\hline BS-ZTT & $1.40 \pm 0.16$ & $2.27 \pm 0.27$ & 23.0 & 78.0 & -2.560 & $0.011 *$ \\
\hline TI-VAS & $7.30 \pm 2.02$ & $29.0 \pm 8.87$ & 25.5 & 80.5 & -2.090 & $0.037 *$ \\
\hline Frequency of Illness (per year) & $3.10 \pm 0.85$ & $1.90 \pm 0.32$ & 39.0 & 105.0 & -1.160 & 0.246 \\
\hline
\end{tabular}

*denotes statistical significance $(\mathrm{p}<0.05)$ 
Matthew J. Zdilla and Leah D. Starkey / American Journal of Immunology 10 (2): 107-113, 2014

Table 3. Perception of either $10 \mathrm{~mL}$ of distilled water or $0.1 \%$ zinc sulfate solution with zinc taste acuity measurements and salivary carbonic anhydrase VI concentrations

\begin{tabular}{|c|c|c|c|c|c|}
\hline Group* & Sex & BS-ZTT & TI-VAS & [CA6] (ug/ml) & Subjective description \\
\hline \multirow{10}{*}{ Control } & Male & 1 & 0 & 14.84 & N/A \\
\hline & Male & 1 & 5 & 10.74 & "No taste" \\
\hline & Male & 2 & 14 & 1.69 & "Mouth dry, not much taste, tasted dirty" \\
\hline & Male & 1 & 0 & 5.33 & N/A \\
\hline & Male & 2 & 5 & 3.27 & "My mouth is kind of dry" \\
\hline & Female & 2 & 8 & 12.00 & "Mildly bitter" \\
\hline & Female & 1 & 11 & 11.96 & "Tasted like water" \\
\hline & Female & 2 & 18 & 14.69 & "Foggy water" \\
\hline & Female & 1 & 12 & 12.48 & "Like distilled water" \\
\hline & Female & 1 & 0 & 3.43 & N/A \\
\hline \multirow[t]{11}{*}{ Experimental } & Male & 2 & 15 & 14.27 & "Dry taste" \\
\hline & Male & 2 & 35 & 12.58 & "Sour taste" \\
\hline & Male & 4 & 96 & 15.13 & "Extremely sour and bitter. Slight metallic taste" \\
\hline & Male & 2 & 8 & 4.67 & "Salty" \\
\hline & Male & 1 & 0 & 3.60 & N/A \\
\hline & Male & 2 & 12 & 5.67 & "Numbness, sour" \\
\hline & Female & 4 & 64 & 13.54 & "Metally and dry" \\
\hline & Female & 2 & 34 & 13.93 & "Really no taste, but can tell it's not water" \\
\hline & Female & 2 & 2 & 10.90 & $\begin{array}{l}\text { "Not really much different than the taste of water. } \\
\text { Mouth just feels dry after, rather than wet." }\end{array}$ \\
\hline & Female & 2 & 13 & 2.81 & "Slight taste" \\
\hline & Female & 2 & 40 & 4.48 & "Dry, chalky" \\
\hline
\end{tabular}

*The control group received a test solution of $10 \mathrm{~mL}$ distilled water. The experimental group received a test solution of $10 \mathrm{~mL} 0.1 \%$ zinc sulfate solution

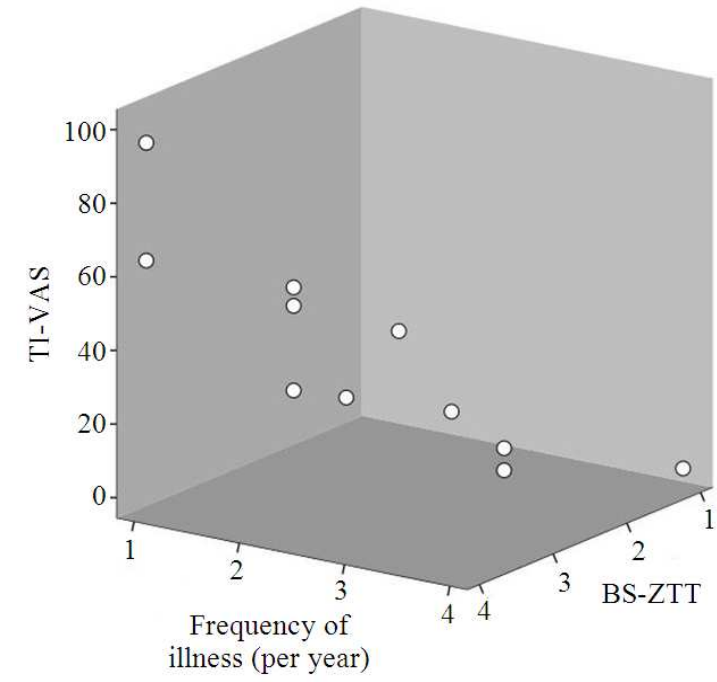

Fig. 2. Zinc sulfate taste acuity, as measured by both the BSZTT and TI-VAS, is correlated with self-reported frequency of illness (participant's self-reported response to a question asking, over the past three years, about how often, per year, the participant was sick). Among the 11 individuals tested with a $0.1 \%$ zinc sulfate solution, the BS-ZTT was moderately correlated with frequency of illness $\left(r_{s}=-0.64, p=0.034\right)$ and the TI-VAS was strongly correlated with the frequency of illness $\left(r_{s}=-0.81, p=0.003\right)$

\subsection{Zinc Sulfate Taste Acuity and Frequency of Illness}

There was a strong statistically significant correlation between BS-ZTT and TI-VAS data in the experimental group $\left(r_{s}=0.78, p=0.004, \mathrm{n}=11\right)$. Also, among those tested with the $0.1 \%$ zinc sulfate solution, a moderate statistically significant correlation was found between the frequency of illness and BS-ZTT scores $\left(r_{s}=-0.64, p=0.034, \mathrm{n}=11\right)$. Likewise, a strong statistically significant correlation was found between frequency of illness and TI-VAS scores $\left(r_{s}=-\right.$ 0.81, $p=0.003, \mathrm{n}=11$ ) (Fig. 2).

\section{DISCUSSION}

Our findings suggest that measurements of zinc sulfate taste acuity may reflect salivary CA6 levels. CA6, itself, has broad importance with regard to oral health and therefore, health in general. CA6 modifies oral $\mathrm{pH}$ and has been shown to be a factor in the etiology of dental caries (Kivelä et al., 1999; Leinonen et al., 1999; Culp et al., 2011). Decayed missing and filled teeth data suggest CA6 to be cariostatic (Kivelä et al., 1999), likely by maintaining its enzymatic activity as part of the enamel pellicle (Leinonen et al., 1999). A study conducted in preschool children noted that variation of 
salivary CA6 activity was negatively correlated with caries (Frasseto et al., 2012). Conversely, other research has noted that CA6 may have a cariogenic role by favoring colonization of $S$. mutans (Culp et al., 2011). Because our findings demonstrate a correlation between CA6 concentrations and zinc sulfate taste acuity and CA6 has been shown to be a factor in the etiology of dental caries, zinc sulfate taste acuity testing, then, may be useful as a screening test to indicate a predisposition for dental caries.

Because both the BS-ZTT and TI-VAS were correlated with the frequency of illness among the experimental group, zinc sulfate taste acuity may be reflective of immune function, at least retrospectively. Inadequate zinc levels are known to affect taste function, potentially via CA6 and taste bud growth and development (Shatzman and Henkin, 1981; Henkin et al., 1999b; Yagi et al., 2013). Inadequate zinc levels also negatively affect immune function (Knoell and Liu, 2010; Prasad, 2008; 2009). Therefore, we speculate that zinc sulfate taste acuity and frequency of illness may be related via bioavailable zinc. Similarly, studies have correlated zinc sulfate taste acuity with serum zinc levels throughout pregnancy (Garg et al., 1993) and zinc levels in sweat (Eaton et al., 2004).

The research presented herein is greatly limited by a small sample size. Additionally, the study did not account for certain variables which have been demonstrated to effect levels of CA6. For example, polymorphisms of CA6 have been associated with both alterations in taste function and the amount of CA6 produced (Peres et al., 2010; Aidar et al., 2013). Also, when salivary flow rate slows, such as in the case of acute hyperglycemia, CA6 levels decrease (Negrato and Tarzia, 2010). Additionally, the autonomic nervous system may also play a role in the amount of CA6 produced as has been suggested in a study of sheep (Fernley et al., 1991).

\section{CONCLUSION}

Although this pilot study is limited by a small sample size, the implications of the findings herein are still noteworthy. The results of the study demonstrate that zinc sulfate taste acuity, as measured by the BS-ZTT, is correlated with salivary CA6 levels. Therefore, it appears likely that CA6, a zinc dependent enzyme, is important in zinc sulfate taste acuity. Also, zinc sulfate taste acuity testing may be an indirect measurement of CA6 levels, which could have broad applications. Zinc sulfate taste acuity may also be a retrospective indicator of illness frequency. Future research should further explore the relationship between zinc sulfate taste acuity, salivary CA6 and illness.

\section{ACKNOWLEDGEMENT}

Research was made possible by a West Liberty University Faculty Development Grant and a NASA West Virginia Space Grant Consortium Research Enhancement Award.

\section{REFERENCES}

Aidar, M., R. Marques, J. Valjakka, N. Mononen and T. Lehtimäki et al., 2013. Effect of genetic polymorphisms in CA6 gene on the expression and catalytic activity of human salivary carbonic anhydrase VI. Caries Res., 47: 414-420. DOI: 10.1159/000350414

Bryce-Smith, D. and R.I.D. Simpson, 1984a. Case of anorexia nervosa responding to zinc sulphate. Lancet, 2: 350-350. DOI: 10.1016/S01406736(84)92717-X

Bryce-Smith, D. and R.I.D. Simpson, 1984b. Anorexia, depression and zinc deficiency. Lancet, 2: 11621163. DOI: 10.1016/S0140-6736(84)91605-2

Culp, D.J., B. Robinson, S. Parkkila, P.W. Pan and M.N. Cash et al., 2011. Oral colonization by streptococcus mutans and caries development is reduced upon deletion of carbonic anhydrase VI expression in saliva. Biochim. Biophys. Acta, 1812: 1567-1576. DOI: 10.1016/j.bbadis.2011.09.006

Eaton, K.K., I.G. Betteley and M. Harris, 2004. Diagnosing human zinc deficiency. A comparison between the Bryce-Smith taste test and the sweat mineral analysis. J. Nutr. Environ. Med., 14: 83-87. DOI: $10.1080 / 13590840410001734910$

Fernley, R.T., R.D. Wright and J.P. Coghlan, 1991. Radioimmunoassay of carbonic anhydrase VI in saliva and sheep tissues. Biochem. J., 274: 313-316. PMID: 1900985

Frasseto, F., T.M. Parisotto, R.C. Peres, M.R. Marques and S.R. Line et al., 2012. Relationship among salivary carbonic anhydrase VI activity and flow rate, biofilm $\mathrm{pH}$ and caries in primary dentition. Caries Res., 46: 194-200. DOI: 10.1159/000337275

Garg, H.K., K.C. Singal and Z. Arshad, 1993. Zinc taste test in pregnant women and its correlation with serum zinc level. Ind. J. Physiol. Pharmacol., 37: 318-322. PMID: 8112809 
Gruner, T. and R. Arthur, 2012. The accuracy of the zinc taste test method. J. Alternative Complementary Med., 18: 541-550. DOI: 10.1089/acm.2011.0298

Henkin, R.I., B.M. Martin and R.P. Agarwal, 1999a. Efficacy of exogenous oral zinc in treatment of patients with carbonic anhydrase VI deficiency. Am. J. Med. Sci., 318: 392-405. PMID: 10616164

Henkin, R.I., B.M. Martin and R.P. Agarwal, 1999b. Decreased parotid saliva gustin/carbonic anhydrase VI secretion: An enzyme disorder manifested by gustatory and olfactory dysfunction. Am. J. Med. Sci., 318: 380-391. PMID: 10616163

Kivelä, J., S. Parkkila, A.K. Parkkila, J. Leinonen and H. Rajaniemi, 1999. Salivary carbonic anhydrase VI. J. Physiol., 520: 315-320. DOI: 10.1111/j.14697793.1999.t01-1-00315.x

Knoell, D.L. and M.J. Liu, 2010. Impact of zinc metabolism on innate immune function in the setting of sepsis. Int. J. Vitamin Nutr. Res., 80: 271-277. DOI: 10.1024/0300-9831/a000034

Leinonen, J., J. Kivelä, S. Parkkila, A.K. Parkilla and H. Rajaniemi, 1999. Salivary carbonic anhydrase isoenzyme VI is located in the human enamel pellicle. Caries Res., 33: 185-190. DOI: 10.1159/000016515

Mahomed, K., D. James, J. Golding and R. McCabe, 1993. Failure to taste zinc sulphate solution does not predict zinc deficiency in pregnancy. Eur. J. Obstetr. Gynecol. Reproductive Biol., 48: 169-175. DOI: 10.1016/0028-2243(93)90084-P

Murakami, H. and W.S. Sly, 1987. Purification and characterization of human salivary carbonic anhydrase. J. Biol. Chem., 262: 1382-1388. PMID: 2433278

Negrato, C.A. and O. Tarzia, 2010. Buccal alterations in diabetes mellitus. Diabetol. Metabolic Syndrome. DOI: $10.1186 / 1758-5996-2-3$
Parkkila, S., A.K. Parkkila and H. Rajaniemi, 1995. Circadian periodicity in salivary carbonic anhydrase VI concentration. Acta Physiol. Scandinavica, 154: 205-211. PMID: 7572216

Peres, R.C., G. Camargo, L.S. Mofatto, K.L. Cortellazzi and M.C. Santos et al., 2010. Association of polymorphisms in the carbonic anhydrase 6 gene with salivary buffer capacity, dental plaque $\mathrm{pH}$ and caries index in children aged 7-9 years. Pharmacogenom. J., 10: 114-119. DOI: 10.1038/tpj.2009.37

Prasad, A.S., 2008. Zinc in human health: Effect of zinc on immune cells. Molecular Med., 14: 353-357. DOI: 10.2119/2008-00033.Prasad

Prasad, A.S., 2009. Zinc: Role in immunity, oxidative stress and chronic inflammation. Current Opin. Clin. Nutr. Metabolic Care, 12: 646-652. DOI: 10.1097/MCO.0b013e3283312956

Shatzman, A.R. and R.I. Henkin, 1981. Gustin concentration changes relative to salivary zinc and taste in humans. Proc. Nat. Acad. Sci. USA, 78: 3867-3871. PMID: 6943587

Sly, W.S. and P.Y. Hu, 1995. Human carbonic anhydrases and carbonic anhydrase deficiencies. Ann. Rev. Biochem., 64: 375-401. DOI: 10.1146/annurev.bi.64.070195.002111

Thatcher, B.J., A.E. Doherty, E. Orvisky, B.M. Martin and R.I. Henkin, 1998. Gustin from human parotid saliva is carbonic anhydrase VI. Biochem. Biophys. Res. Commun., 250: 635-641. PMID: 9784398

Yagi, T., A. Asakawa, H. Ueda, S. Ikeda and S. Miyawaki et al., 2013. The role of zinc in the treatment of taste disorders. Recent Patents Food Nutr. Agric., 5: 44-51. PMID: 23305423 